\title{
Adolescents' health service utilization pattern and preferences: Consultation for reproductive health problems and mental stress are less likely
}

\author{
${ }^{1}$ Frehiwot Berhane, ${ }^{2}$ Yemane Berhane, ${ }^{2}$ Mesganaw Fantahun
}

\begin{abstract}
Background: Despite the growing health needs of adolescents due to intrinsic and extrinsic factors, health services in developing countries are not prepared to provide appropriate care due to inadequate awareness of adolescent health needs, and inadequate training and capacity of the service providers.

Methods: A cross-sectional survey, to assess adolescents' health service utilization pattern, their attitudes towards the existing health services and their preferences was conducted in selected schools in Addis Ababa using an anonymous self-administered questionnaire.

Results: A total of 2,647 students from 13 high schools participated in the study. Of these, 1,177(44.5\%) were males and 1,470(55.5\%) were females. Considerable proportion of the adolescents reported that existing health services are inaccessible (30.5\%), unaffordable (20.2\%) and unacceptable (24.2\%). The major barriers to utilizing reproductive health services are feeling of embarrassment $(72.0 \%)$ and fear of being seen by parents or people who know them (67.8\%). Adolescent's preference regarding the service place and person serving varies widely; but the majority prefers special service hours designated for adolescents (70.1\%), and a discounted price or free service (80.0\%). Disclosing reproductive health problems and mental stress to parents, and seeking appropriate medical care for these problems is much less likely compared to other non-reproductive physical health problems.

Conclusion: Adolescents are less likely to utilize existing health services when facing reproductive health problems and suffering from mental stress. Innovative and youth friendly approaches with due consideration of the heterogeneity of their needs should be adapted in order to increase accessibility and utilization of appropriate health services. [Ethiop.J.Health Dev. 2005;19(1):29-36]
\end{abstract}

\begin{abstract}
Introduction
Adolescence is transitional period from childhood to adulthood, characterized by significant physiological, psychological and social changes. WHO defines adolescents as those in the age group of 10-19 and youth $10-24$ years $(1,2)$. The adolescent population in Ethiopia has been increasing during the last few decades. Currently, adolescents constitute about $24 \%$ while young adults $10-24$ years constitute about $30 \%$ of the total population (3). Our world currently cares for a historic highest number of adolescents; about 1.2 billion adolescents need proper education, health and other life skills to ensure a better future for themselves and their countries $(1,2)$.
\end{abstract}

Adolescents, having survived all childhood health problems, have been enjoying a relatively low morbidity and mortality period in the past. At present, due to changing conditions due to civilization, urbanization and life style, the health of adolescents is increasingly at stake. Sexually transmitted diseases, HIV/AIDS and other reproductive health problems are the greatest threats to their well-being. However, despite the growing needs, there is no adequate health service or counseling specifically suitable for this specific age group unlike children, mothers or adults (4-6).
The life style and reactions of adolescents vary from those of adults. Adolescents, who are trying to find their identity and independence, behave and communicate differently than adults when they come to health services. The usual patient - physician relationship may not help health workers to understand their problems. The health system must therefore adapt a suitable strategy through restructuring, formal training or inservice self-awareness sessions to make a more friendly communication with adolescents and thus be of better help to them. Any rigid, judgmental position or defensive and stereotypic expectations concerning adolescent behavior must be abolished. Usually, teenagers respond well if approached in an individualized, collaborative and negotiated manner. Thus, health services to adolescents must be delivered in an atmosphere of trust and confidentiality to make every contact a milestone visit. This will enable to successfully attract, serve and retain the young clients $(6,7)$.

Addressing the preferences of adolescents to the different attributes of health services and ensuring supportive environment from parents and relevant others

${ }^{1}$ Ethiopian Public Health Association, Addis Ababa, Ethiopia; ${ }^{2}$ Department of Community Health, Faculty of Medicine, Addis Ababa University, Addis Ababa, Ethiopia 
would maximize the service utilization rate. Hence, ensuring the involvement of adolescents together with the community and government agencies in planning, implementation and evaluation of interventions meant for them should be a prerequisite for the successful implementation of adolescent reproductive health services (8-12).

The main purpose of this study was therefore; to describe the health service utilization pattern of adolescents, assess their attitudes towards existing services, and their preference of services in terms of place, person and time. This will help decision makers, health care planners and implementers to provide appropriate reproductive health services to adolescents.

\section{Methods}

The study employed cross-sectional survey design. It was conducted in selected schools in Addis Ababa, Ethiopia, in May 2000. The target population was senior secondary school students enrolled in the year 1999/2000 (13). These were 130,000 students in 41 senior secondary schools in Addis Ababa out of 23 were owned by the government. The Government schools were distributed unevenly in the city, which was divided then into six zones. The Education Bureau generally assigned students to the nearby school from their residence. All schools primarily established for Ethiopian students in the city, without special regulation (like the prison, boarding and foreign community schools) that makes them different from regular schools were included in the study.

Sample size (SS) was calculated using computer program with very conservative assumptions in order to get larger sample size that would allow the study to look into various aspects of adolescent. Accordingly, the SS was 3028 students. Multistage sampling technique was employed in order to select a representative sample of students. Samples were selected from different categories of schools proportional to their size of the student population. Attention was also given to proportionally select students from all zones of the city. In the selected schools one section was selected from each grade level $\left(9^{\text {th }} 10^{\text {th }}\right.$ and $\left.11^{\text {th }}\right)$ randomly except for grade $12^{\text {th }}$ that have finalized their national examination and not available for the study.

Data was collected using a pre tested self-administered anonymous structured close-ended questionnaire. The questionnaire was prepared based on the available literature and the opinion generated from the adolescents themselves during Focus Group Discussions conducted prior to the survey in schools that were not included in this study. The questionnaire was first prepared in English and translated later into the national language (Amharic).
Students who gave their consents to participate in the study received elaborated explanation on the purpose of the study and the type of questions and how to answer by trained facilitators. Furthermore, to ensure privacy and enhance honest and frank responses, male and female students were seated wide apart in separate classrooms. Slightly different questioners were used for male and female to accommodate different questions by sex.

Data processing and analysis were done using Epi Info version 6.04 and SPSS 10.1 statistical programs. Frequencies of the variables of interest and cross tabulations were done to determine the magnitude of the problems. Statistical significance was considered at pvalue less than 0.05 .

\section{Results}

Out of the 3028 school adolescents invited for the study 2656 (87.7\%) completed the questionnaire. Of these nine were excluded due to incompleteness and inconsistency of responses. Thus, analysis was made for the 2647, out of which 1177 (44.5\%) were male and 1470 (55.5\%) female. The majority, 2191 (89.2\%) were in the age group 15-19 years; and 1774 (67.4\%) were living with both parents. Considerable proportion, 1030 (39.6\%), of students had mothers without formal education, while 934 (36.2\%) of fathers had higher-level education. Nine hundred seventy two $(38.0 \%)$ of the students had both parents working for paid job (Table 1).

Adolescents' responses to illness in the last three months are categorized into three: $504(19.0 \%)$ reported no illness, 1469 (55.5\%) reported physical illnesses (fever, headache, abdominal problems, chest pain, weight loss, skin disease, toothache, ear and throat problems, and injury), 62 (2.3\%) reported reproductive health problems (urgency and burning urination, and genital discharge), and 612 (23.1\%) reported mental distress.

The advice-seeking pattern of adolescents for the three categories of problems faced during the last three months is presented in figure 1 . The adolescents tend to seek more advice from parents and health professionals for nonreproductive health physical illnesses as compared to reproductive health and mental stress problems. For the latter they tend to seek advice either from peers or no one. For the same period and the same category of illnesses adolescents are less likely to consult any category of health service provider when they face reproductive health problems and mental stress (Figure 2). 
Table 1: Socio-demographic and parental characteristics of the school adolescents, Addis Ababa, May 2000

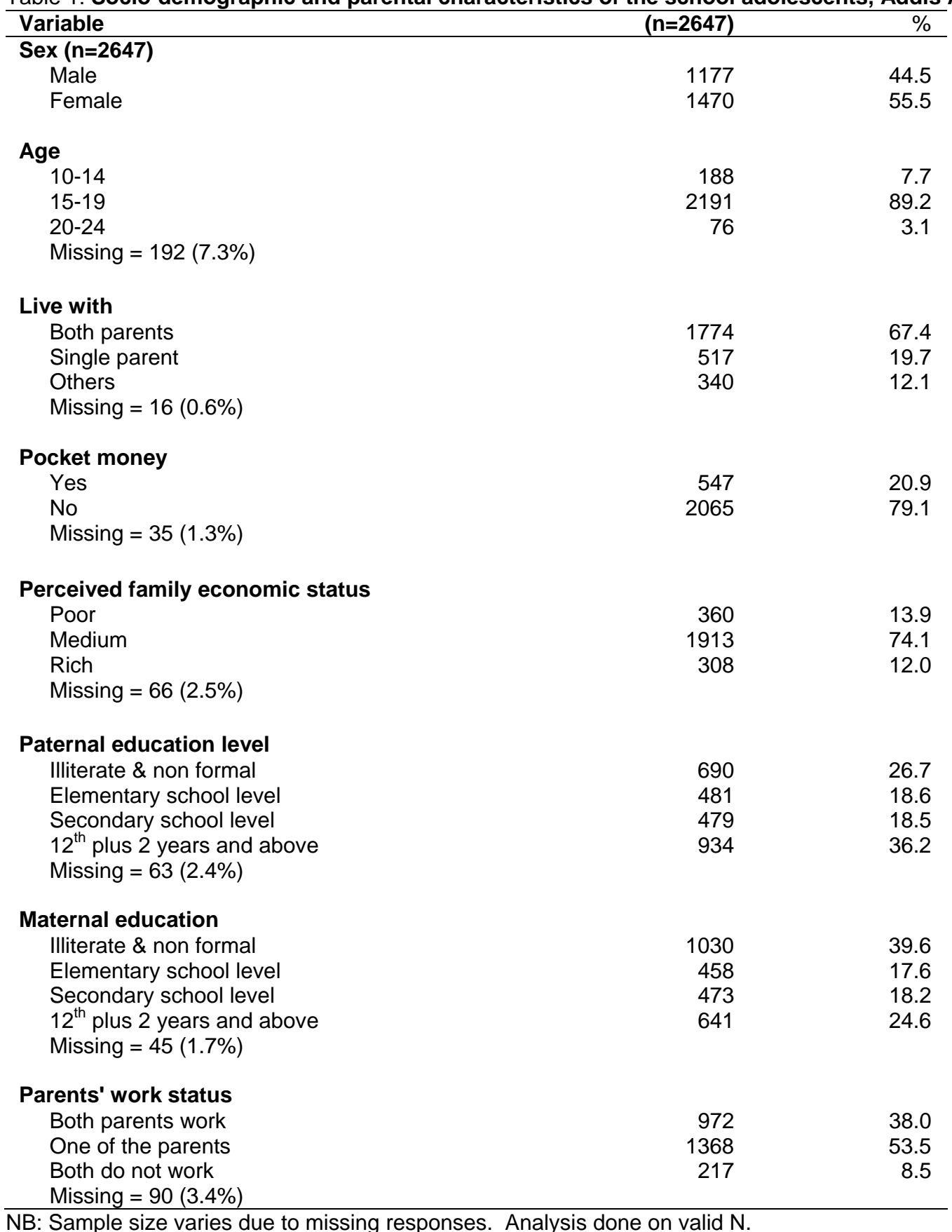




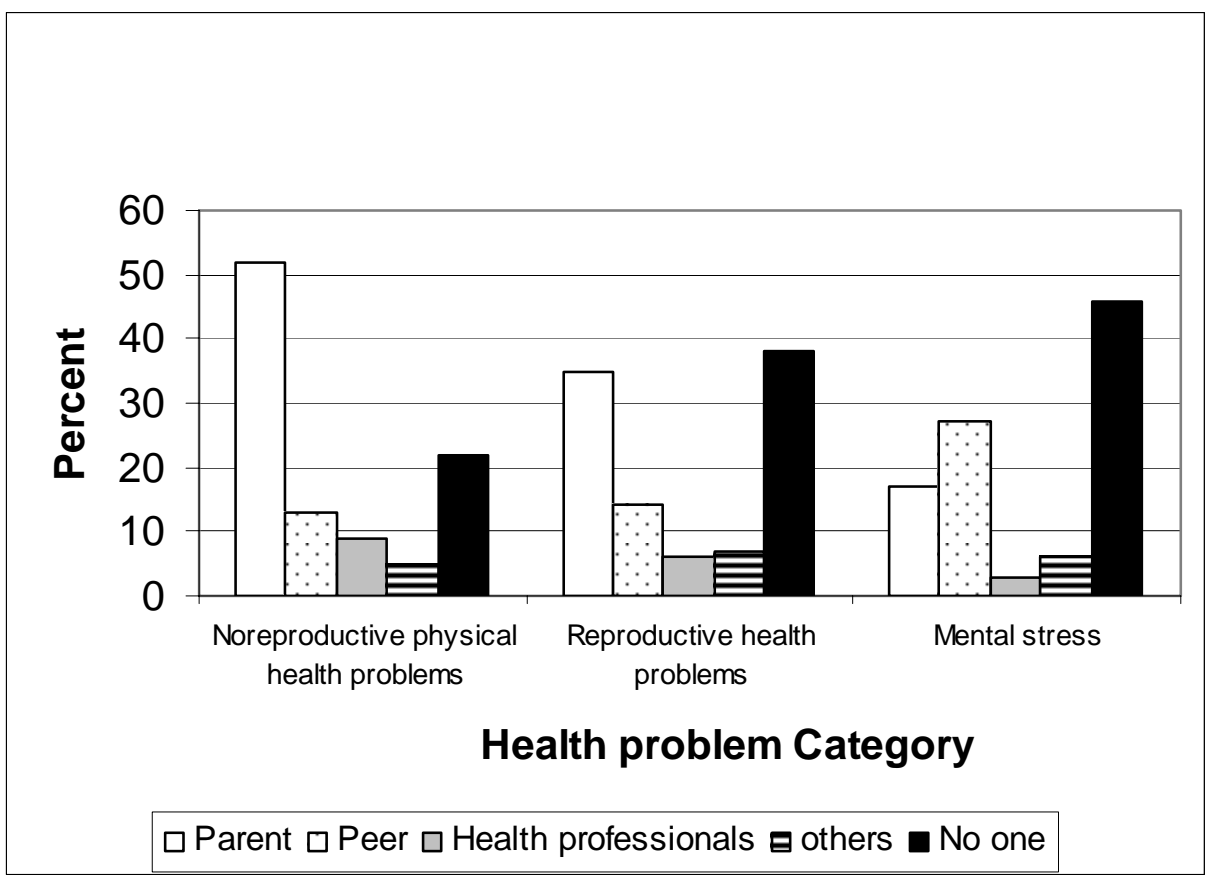

Figure 1: First advice sought by school adolescents for their health problems, Addis Ababa, May 2000



Figure 2: Health services utilization pattern by adolescents for their health problems, Addis Ababa, May 2000 
Generally, the government health institutions received a higher rating in terms of accessibility and affordability of health services to respondents. Considerable proportion of adolescents reported that reproductive health services are not accessible 783(30.5\%), affordable 523(20.2\%) and acceptable $610(24.2 \%)$ in any of the existing health services for adolescents (Table2).

Table 2: Accessibility, affordability, and acceptability of reproductive health services as perceived by adolescents, Addis Ababa, May 2000

\begin{tabular}{|c|c|c|}
\hline Variables & $\mathrm{N}$ & $\%$ \\
\hline \multicolumn{3}{|l|}{ Accessibility $(n=2657)$} \\
\hline Government health institutions & 843 & 32.8 \\
\hline Private health institutions & 569 & 22.1 \\
\hline Village health services & 106 & 4.1 \\
\hline \multicolumn{3}{|l|}{ Health service given in } \\
\hline Pharmacies & 31 & 1.2 \\
\hline School clinics & 95 & 3.7 \\
\hline Others & 145 & 5.6 \\
\hline \multicolumn{3}{|l|}{ No health service is accessible for } \\
\hline the youth & 783 & 30.5 \\
\hline \multicolumn{3}{|l|}{ Missing = $75(2.8 \%)$} \\
\hline \multicolumn{3}{|l|}{ Affordability } \\
\hline Government health institutions & 1142 & 44.2 \\
\hline Private health institutions & 186 & 7.2 \\
\hline Unofficial village health services & 133 & 5.2 \\
\hline Pharmacies & 36 & 1.4 \\
\hline School health services & 116 & 4.5 \\
\hline Others & 73 & 2.8 \\
\hline No affordable health service & 523 & 20.2 \\
\hline Do not know & 375 & 14.5 \\
\hline \multicolumn{3}{|l|}{ Missing = $63(2.4 \%)$} \\
\hline \multicolumn{3}{|l|}{ Acceptability } \\
\hline Good acceptability & 726 & 28.9 \\
\hline Medium acceptability & 1018 & 40.5 \\
\hline Unacceptable & 610 & 24.2 \\
\hline Others & 161 & 6.4 \\
\hline Missing = $132(5.0 \%)$ & & \\
\hline
\end{tabular}

NB. Sample size varies due to missing responses. Analysis is done on valid sample $(\mathrm{N})$.

The major barriers in utilizing reproductive health services by adolescents are fear of being seen by parents or people whom they know (72\%), and embarrassment demand to reproductive health services (67.8\%). Second category of barriers includes inconvenience of the time service is provided and high cost of service. Negative attitudes toward the service providers because of not keeping confidentiality and being judgmental also constitute a significant barrier (Table 3).

Table 3: Attitude of adolescents towards the existing reproductive health services, Addis Ababa, May 2000

\begin{tabular}{|c|c|c|}
\hline Variables $(n=2647)$ & $\mathbf{N}$ & $\%$ \\
\hline \multicolumn{3}{|c|}{$\begin{array}{l}\text { Fear of being seen by parents or } \\
\text { others }\end{array}$} \\
\hline Yes & 1852 & 72.0 \\
\hline No & 334 & 13.0 \\
\hline Do not know & 387 & 15.0 \\
\hline \multicolumn{3}{|l|}{ Missing = $74(2.8 \%)$} \\
\hline \multicolumn{3}{|c|}{ Embarrassment at needing RHS } \\
\hline Yes & 1738 & 67.8 \\
\hline No & 364 & 14.2 \\
\hline Do not know & 462 & 18.0 \\
\hline \multicolumn{3}{|l|}{ Missing = $83(3.1 \%)$} \\
\hline \multicolumn{3}{|c|}{$\begin{array}{l}\text { Providers are judgmental and } \\
\text { unfriendly }\end{array}$} \\
\hline Yes & 933 & 36.3 \\
\hline No & 837 & 32.6 \\
\hline Do not know & 800 & 31.1 \\
\hline \multicolumn{3}{|l|}{ Missing = $77(2.9 \%)$} \\
\hline \multicolumn{3}{|c|}{ Providers keep confidentiality } \\
\hline Yes & 1070 & 41.9 \\
\hline No & 554 & 21.7 \\
\hline Do not know & 928 & 36.4 \\
\hline \multicolumn{3}{|l|}{ Missing = $95(3.6 \%)$} \\
\hline \multicolumn{3}{|l|}{$\begin{array}{l}\text { The time of service is not } \\
\text { convenient }\end{array}$} \\
\hline Yes & 1333 & 52.0 \\
\hline No & 520 & 20.2 \\
\hline Do not know & 715 & 27.8 \\
\hline \multicolumn{3}{|l|}{ Missing $=79(3.0 \%)$} \\
\hline \multicolumn{3}{|c|}{ Service fees are expensive } \\
\hline Yes & 1402 & 57.0 \\
\hline No & 370 & 15.1 \\
\hline Do not know & 687 & 27.9 \\
\hline Missing = $188(7.1 \%)$ & & \\
\hline
\end{tabular}

NB. Sample size varies due to missing responses. Analysis done on valid $\mathrm{N}$.

With regards to the preference of service delivery place and distance from the residence area there was no compete consensus among participating adolescents. However, 1776 (70.1\%) preferred special service hours, 1127 (44.3\%) preferred the health service provider to be young and of the same sex, and 1351 (52.9\%) expressed their preference for discounted fees for adolescents (Table 4). 
Table 4: Preference of adolescents on ARHS arrangements, Addis Ababa, May 2000

\begin{tabular}{|c|c|c|}
\hline Variables & $\mathbf{N}$ & $\%$ \\
\hline \multicolumn{3}{|l|}{ Preference by place } \\
\hline \multicolumn{3}{|l|}{ In the existing services with } \\
\hline special approach to adolescents & 552 & 21.6 \\
\hline In special rooms with in the existing HS & 389 & 15.2 \\
\hline In separate Adolescent health institutions & 659 & 22.3 \\
\hline In school health services & 197 & 7.7 \\
\hline In youth center & 501 & 19.6 \\
\hline Others & 344 & 13.5 \\
\hline \multicolumn{3}{|l|}{ Missing = $95(3.6 \%)$} \\
\hline \multicolumn{3}{|l|}{ Preference by Time } \\
\hline Usual working hours & 524 & 20.7 \\
\hline Specially hours for adolescents & 1776 & 70.1 \\
\hline Others & 233 & 9.2 \\
\hline \multicolumn{3}{|l|}{ Missing = $114(4.3 \%)$} \\
\hline \multicolumn{3}{|l|}{ Preference of service provider } \\
\hline Young \& of the same sex & 1127 & 44.3 \\
\hline Young \& any sex & 332 & 13.1 \\
\hline Matured \& the same sex & 503 & 19.8 \\
\hline Matured \& any sex & 239 & 9.4 \\
\hline No difference & 343 & 13.5 \\
\hline \multicolumn{3}{|l|}{ Missing = $103(4.0 \%)$} \\
\hline \multicolumn{3}{|l|}{ Preference on service fees } \\
\hline At the usual rate & 192 & 7.5 \\
\hline At special discount for adolescent & 1351 & 52.9 \\
\hline Free of charge for adolescents & 691 & 27.1 \\
\hline Other & 105 & 4.1 \\
\hline Do not know & 213 & 8.4 \\
\hline \multicolumn{3}{|l|}{ Missing = $95(3.6 \%)$} \\
\hline \multicolumn{3}{|l|}{ Preference on distance from residence } \\
\hline Near residency area & 966 & 38.2 \\
\hline Outside of residency area & 945 & 37.4 \\
\hline Others & 79 & 3.1 \\
\hline Do not know & 538 & 21.3 \\
\hline Missing = $119(4.5 \%)$ & & \\
\hline
\end{tabular}

\section{Discussion}

The study indicated that the existing health services are not fully accessible, affordable and acceptable to adolescents. It also indicated that adolescents prefer to consult either peers or suffer in silence when they face reproductive health problems and mental stress. The majority of adolescents who suffered illness during the last three months did not seek medical care, particularly more for problems of reproductive health and mental stress.

In agreement with previous reports, adolescents shy away from individuals and institutions that should have provided them with appropriate information, counseling and services in this era of HIV/AIDS where by their sexual reproductive heath problems are increasing $(8,14,15)$. The situation is aggravated by the lack of close parental counseling due to cultural taboos and institutional weaknesses related to lack of capacities to understand their specific nature and needs to provide them with the appropriate service they disserve.

The study revealed that about one fifth of the respondents live with single parent and about a third of the respondents have both parents going out for paid work, which could have a negative effect on parent adolescent connected-ness that facilitates further intimacy to discuss sensitive issues at this critical stage. This, in addition to the cultural taboo and lack of skills to discuss sensitive issues could have contributed for not seeking first advices from parents, especially for $\mathrm{RH}$ and stress related problems as substantiated by others studies $(8,16,17)$ For effective health service utilization, one of the major components is addressing the enabling environment appropriately. Hence, devising a mechanism to build the capacity of households, neighbors, and the community at large be it residential or school, to create a sustainable supportive enabling environment for adolescents should 
be a major area of focus in the implementation of ARH interventions. $(1,2,8,18)$.

The observed decreasing pattern of utilization of existing health service from non reproductive health to reproductive health problems and mental stress, and the tendency of not utilizing services at all for reproductive health and mental stress related problems indicate that the health service delivery system is not suitable for adolescents (19-21). This could be explained by the finding from the study that the attitude of adolescents towards existing reproductive health services in relation to the settings, the providers and operational issues which is generally stigmatizing and inconvenient. These evidences are similar to those substantiated by other reports $(8,14)$ that described the need for better understanding of the specific nature and needs of adolescent in order to provide services suitable for them based on their preferences.

An interesting finding of this study is that consensus was not reached on the preferences of adolescents on places of services, and provider type which reflect their diversity. For instance, a considerable proportion of adolescents preferred to have services within the existing services as they perceive that it will be difficult for people who know them to tell for what reason they visited the health service. Some adolescents preferred to use services outside of their residential areas in order to overcome the stigma attached to going to youth specific services in their residential area. Despite the variation in preferences all wanted confidential, friendly nonjudgmental, and skilled approaches. Hence, the implication is that there is a need to address the heterogeneity of adolescents and utilizing all possible options and strategies to provide adolescents with the services suitable for them $(2,8,22,23)$.

In conclusion, evidences indicate that in our set up, the exiting health services delivery system is not suitable for adolescent use when it comes to reproductive health problems and mental stress. As a matter of right, it is high time that the health service delivery system considers the special needs of adolescents and work out comprehensive and effective policies and strategies to provide young people with the services appropriate to their needs. Ensuring the involvement of adolescents at all levels of the planning, implementation and evaluation processes as well as properly addressing their family, and the community in which they live is highly recommended to successfully provide friendly health service to adolescents.

\section{Acknowledgment}

The authors extend their gratitude to the Austrian Embassy Development Cooperation for sponsoring the study. The Department of Community Health of the Faculty of Medicine, Addis Ababa University, is acknowledged for the all round support throughout the study period. All institutions and individuals who facilitated the activities of this survey in one-way or another are well appreciated and thanked. Last but not least, our heartfelt thanks and best wishes go to the adolescents who participated in the survey.

\section{References}

1. UNFPA, Sexual and Reproductive Health of Adolescents: a review of UNFPA assistance. Technical Report N 48, 1998.

2. WHO, Programming for adolescent health and development report of WHO/UNFPA/UNICEF study group on programming for adolescent health WHO, technical report series 886,Geneva 1999.

3. Central Statistics Authority, Population and Housing Census of Ethiopia-Results at country level, Addis Ababa, 1994.

4. Berhane F. Assessment of Reproductive Health Service in Front Line Health Institution, under Addis Ababa Health Bureau. Residency Report, Department of Community Health, Faculty of Medicine, Addis Ababa University. September 1999.

5. Pathfinder International African Regional Office. Adolescent Reproductive Health in Africa: Path into the next century, 1999.

6. Senderowitz J. Adolescent Health reassuring the passage to adulthood, World Bank discussion paper, World Bank Washington DC No: 272, 1995

7. Hofmann AM., Greydanus DE. Adolescent Medicine. Second Edition, 1989,USA.

8. Senderowitz J. Making Reproductive health service youth friendly. Focus on Young Adults, 1999.

9. Kurz KM, Johnson WE, LeFrance E. Adolescent Fertility and Reproductive Health: A Needs Assessment in the English- Speaking Caribbean for the Pew Charitable Trust. International Center for Research on Women. 1995.

10. Marie Stops International. 1995 "A cross Cultural Study of Adolescents" Access to Family Planning and Reproductive Health Education and Service.

11. Weiss E, Whalen D, Gupta GR 1996 Vulnerability and Opportunity: Adolescent and HIV/AIDS in the Developing World. Washington DC. International Center for Women.

12. Reproductive Health Outlook. Adolescent Reproductive Health Program Examples. 2000, http://www.rho.org./html/adol_progexamples.htm (accessed January 2004)

13. Addis Ababa Education Bureau. Annual Educational Booklet. Plan and project service unit. Addis Ababa, 1998/1999.

14. Blum RW. Global trends in Adolescent Health. JAMA, 1991;265(20):2711-2719.

15. UNAIDS. 2004 report of the Global AIDS epidemic. 2004:13-39.

16. Ehetu F, Zkus D, Kebede D. The attitude of students, parents and teachers towards the promotion and 
provision of condoms for adolescents in Ethiopia. Ethiop. J. Health Dev. 1997l;11(1):7-16.

17. Senannayake P, Ladle M. Adolescent Health: changing needs. International Journal of Gynecology and Obstetrics, 1994:137-147.

18. Anderson R. A Behavioral Model of Families’ Use of health services. 1968, Research Series 25, The University of Chicago, 1968.

19. Gebre KK, Azeze B. Survey on condom use among college students. Ethiop J Health Dev. 1995;9(1):711.
20. Gebre ST. Determinants of contraceptive use among urban youth in Ethiopia. Ethiop J Health Dev. 1996;10(2): 97-104.

21. Gebremariam A, Ayele F. Health Concerns and Challenges among Adolescents. Ethiopian Journal of Health Sciences 2000;10(1):37-46.

22. Kambou RZS, Ford C, Chikotola B, Simasiku M. Partnersip for Adolescent Sexual and Reproductive Health Project. CARE, 1998.

23. WHO, Reproductive Health Strategy for the Africa Region 1998-2007. Harare 1998. 
